\title{
Why the Western Pacific Subtropical High Has Extended Westward since the Late 1970s
}

\author{
Tianjun Zhou,* Rucong Yu,* Jie Zhang, ${ }^{+}+$Helge Drange, ${ }^{*}$ Christophe Cassou, ${ }^{\circledR}$ \\ Clara Deser, \& DANIEl L. R. HODSOn,** EMILIA SANCHEZ-GOMEZ, ${ }^{\circledR}$ JiAn Li,*,+ \\ Noel KeEnlyside, ${ }^{++}$XiaOge Xin, ${ }^{*},+$ and Yuko OKumura $\&$ \\ *LASG, Institute of Atmospheric Physics, Chinese Academy of Sciences, Beijing, China \\ ${ }^{+}$Graduate School of the Chinese Academy of Sciences, Beijing, China \\ \# Nansen Environmental and Remote Sensing Center, and Bjerknes Centre for Climate Research, Bergen, Norway \\ ${ }^{\circledR}$ CNRS-CERFACS, Toulouse, France

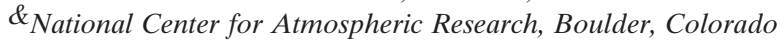 \\ **Center for Atmospheric Modeling, University of Reading, Reading, United Kingdom \\ ${ }^{+}{ }^{+}$Leibniz Institute of Marine Sciences, Kiel, Germany
}

(Manuscript received 12 March 2008, in final form 1 October 2008)

\begin{abstract}
The western Pacific subtropical high (WPSH) is closely related to Asian climate. Previous examination of changes in the WPSH found a westward extension since the late 1970s, which has contributed to the interdecadal transition of East Asian climate. The reason for the westward extension is unknown, however. The present study suggests that this significant change of WPSH is partly due to the atmosphere's response to the observed Indian Ocean-western Pacific (IWP) warming. Coordinated by a European Union's Sixth Framework Programme, Understanding the Dynamics of the Coupled Climate System (DYNAMITE), five AGCMs were forced by identical idealized sea surface temperature patterns representative of the IWP warming and cooling. The results of these numerical experiments suggest that the negative heating in the central and eastern tropical Pacific and increased convective heating in the equatorial Indian Ocean/Maritime Continent associated with IWP warming are in favor of the westward extension of WPSH. The SST changes in IWP influences the Walker circulation, with a subsequent reduction of convections in the tropical central and eastern Pacific, which then forces an ENSO/Gill-type response that modulates the WPSH. The monsoon diabatic heating mechanism proposed by Rodwell and Hoskins plays a secondary reinforcing role in the westward extension of WPSH. The low-level equatorial flank of WPSH is interpreted as a Kelvin response to monsoon condensational heating, while the intensified poleward flow along the western flank of WPSH is in accord with Sverdrup vorticity balance. The IWP warming has led to an expansion of the South Asian high in the upper troposphere, as seen in the reanalysis.
\end{abstract}

\section{Introduction}

The western Pacific subtropical high (WPSH), which occupies about $20 \%-25 \%$ of the Northern Hemispheric surface, plays a major role in the global circulation of the atmosphere and oceans (Liu and $\mathrm{Wu} 2004$ ). Great effort of East Asian scientists has been devoted to the WPSH studies, owing to its dominance on East Asian climate. Residing over the western portion of the subtropical North Pacific basin throughout the year, the WPSH tends to be stronger in summer than in winter.

Corresponding author address: Tianjun Zhou, P.O. Box 9804, LASG, Institute of Atmospheric Physics, Chinese Academy of Sciences, Beijing 100029, China.

E-mail: zhoutj@lasg.iap.ac.cn
The WPSH has been identified as one important component of East Asian summer monsoon (EASM) system (Tao and Chen 1987; Ding 1994; Huang and Wu 1989; $\mathrm{Lau}$ and $\mathrm{Li}$ 1984). The seasonal variation of WPSH is closely related to the onset and withdrawal of EASM. The abrupt northward movement of WPSH from winter to summer is accompanied with abrupt changes in the circulation patterns over the East Asian monsoon area (Ye and Zhu 1958). The distribution of summer rainfall in China is associated with the seasonal variations of WPSH in intensity, structure, and location (e.g., Tao and Xu 1962; Huang and Yu 1962; Huang 1963). The monsoon precipitation along the Yangtze River valley is the product of the mei-yu front, which is quasi stationary and is a characteristic feature of the interaction between the warm, moist winds from the 
tropics and the cold, dry airflow originating from the north (Lau and Li 1984; Zhu et al. 1986; Tao and Chen 1987). The low-level jet along the northwestern edge of WPSH transports a large amount of water vapor into East Asia; any change in WPSH would influence the mei-yu front by affecting the convergence of tropical water vapor with extratropical airflow (Ninomiya and Kobayashi 1999; Zhou and Yu 2005). The WPSH also plays a major role in modulating the weather and climate in Korea and Japan (e.g., Kurihara 1989).

The WPSH exhibits a remarkable seasonal cycle. The mechanisms that underlie the development and maintenance of WPSH are still disputed. The proposed factors include the monsoon diabatic heating (Ting 1994; Hoskins 1996; Rodwell and Hoskins 2001; Chen et al. 2001), land-sea heating (Wu and Liu 2003; Liu et al. 2001, 2004; Miyasaka and Nakamura 2005), diabatic amplification related to the cloud-reduced radiative cooling (Bergman and Hendon 2000), and air-sea interaction (Seager et al. 2003). In addition to seasonal cycle, the WPSH also exhibits interannual changes (Nitta 1987; Kurihara and Tsuyuki 1987; Huang and Sun 1992; Lu 2001; Lu and Dong 2001; Sui et al. 2007; Wu and Zhou 2008). The interannual variability of large-scale quasi-stationary EASM frontal zones is dominated by the position, shape, and strength of WPSH. When the WPSH becomes stronger and shifts toward the equator, the rainband is located along the Yangtze River valley (Zhou and Yu 2005).Variations of WPSH are crucial to the understanding of interannual variations in the meridional structure of the monsoon-sea surface temperature (SST) relationship (Chang et al. 2000a,b).

East Asian climate has experienced an interdecadal scale transition since the late 1970s (Hu 1997; Wang 2001; $\mathrm{Hu}$ et al. 2003; Yu et al. 2004; Li et al. 2005; Xin et al. 2006; Yu and Zhou 2007). This transition is also evident in WPSH (Hu 1997; Gong and Ho 2002; He and Gong 2002). Since the late 1970s, the WPSH has extended westward (Fig. 1), which has resulted in a rainband shift over China, with excessive rainfall along the middle and lower reaches of the Yangtze River valley, and deficient rainfall in north China (e.g., Hu et al. 2003; Yu and Zhou 2007). The mechanism relevant to the westward extension of WPSH remains unresolved. Some statistical analyses have linked the decadal shift of WPSH with the change of ocean temperature. Hu (1997) found that the interdecadal variability of summer precipitation and temperature in East Asia is largely influenced by the changes of SST and convective activity over the tropical Indian Ocean-western Pacific (IWP). Gong and Ho (2002) also suggests the IWP warming as a driving mechanism. However, statistical analyses only provide a hypothesis of relevant mechanisms. The role of ocean forcing in producing the changes of WPSH remains to be clarified. The present study aims to explore the causes for the westward extension of WPSH by addressing the question of whether the IWP SST change has been mostly relevant to the decadal scale shift of WPSH. We employ an idealized SST-forcing atmospheric general virculation model (AGCM) approach to gain insight on this question and to quantify the robustness of IWP impacts on the WPSH. Our results suggest that the warming trend of IWP is in favor of the westward extension of WPSH since the late 1970s via the negative heating in the central and eastern tropical Pacific and increased monsoon condensational heating in the equatorial Indian Ocean/Maritime Continent.

The rest of the paper is organized as follows. We introduce the model experiment and analysis method in section 2 . We then present the analyses of model results in section 3. A discussion is given in section 4. Section 5 summarizes the study and its findings.

\section{Experiments and analysis method}

Since 1977 tropical SSTs have increased by approximately $0.4 \mathrm{~K}$ in the IWP relative to the period of 1950 76 (Webster et al. 1999; Hoerling et al. 2001; Deser and Phillips 2006). The aim of our study is to investigate the impacts on climate of the IWP basin-scale warming. To do so, we carried out experiments in which AGCMs were forced by idealized SST patterns representative of the IWP warming. These coordinated experiments were performed as part of the European Union's (EU's) Sixth Framework Programme, Understanding the Dynamics of the Coupled Climate System (DYNAMITE; information online at http://dynamite.nersc.no/). We carried out two sets of experiments in which the IWP SST anomaly was added to (IOP) or subtracted from (ION) the climatology. Note the SST climatology was prescribed in the regions outside of the IWP. In addition to the IOP and ION experiments, we have also performed a control run with prescribed climatological SST throughout global oceans. It is worthwhile to note that examining the response to a single mode of SST variability implicitly assumes that the atmospheric response to many SST modes that make up the total field can be linearly separated.

The SST forcing pattern for the IWP warming experiment was derived from the monthly mean trends in SST between 1951 and 1999. The Hadley Centre sea ice and sea surface temperature (HadISST) dataset is used (Rayner et al. 2003). The full forcing SST pattern, IOP (ION) was generated by adding (subtracting) scaled anomalies (IO') to (from) the SST climatology over the IWP region (roughly bounded by $35^{\circ} \mathrm{S}-25^{\circ} \mathrm{N}, 30^{\circ}-160^{\circ} \mathrm{E}$ ): 
(a) NCEP/NCAR_1980 1999

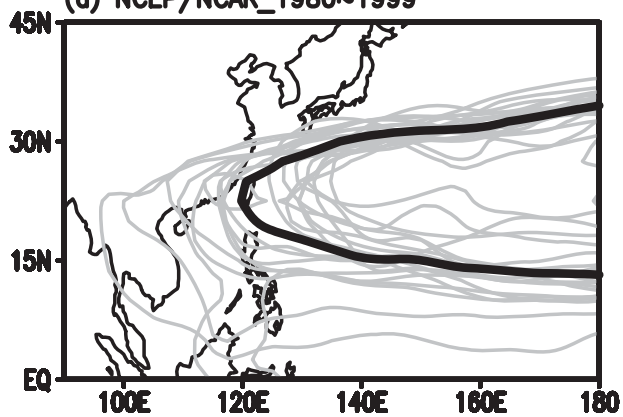

(b) NCEP/NCAR_1958 1979

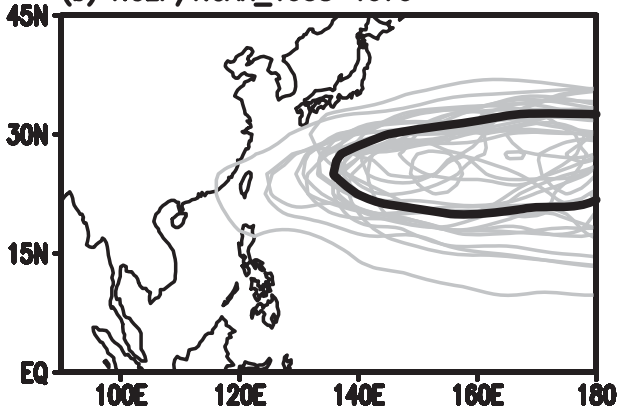

(c) ERA40_1980 1999

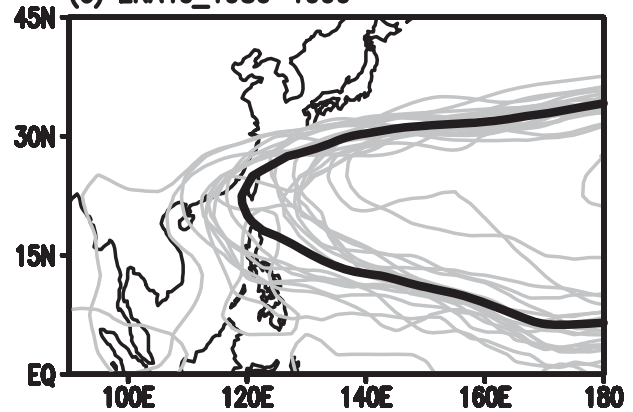

(d) ERA40_1958 1979

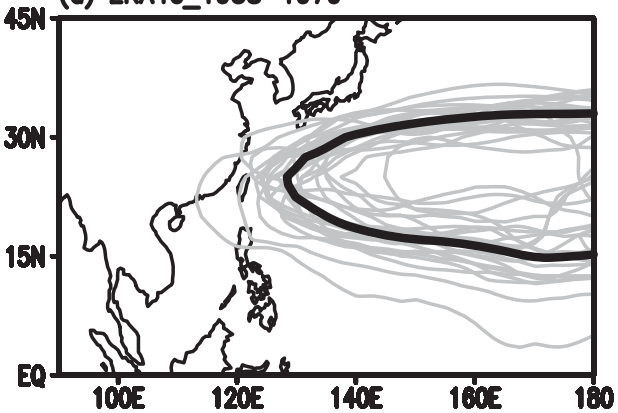

FIG. 1. Contour lines for $5870 \mathrm{gpm}$ of $500-\mathrm{hPa}$ geopotential height for each summer during (a), (c) 1980-99 and (b), (d) 1958-79 from (a), (b) NCEP reanalysis and (c), (d) ERA-40. The thick contour line shows the mean for each time period.

$$
\begin{aligned}
& \mathrm{IOP}=\mathrm{Clim}+23.5 \mathrm{IO}^{\prime}, \\
& \mathrm{ION}=\mathrm{Clim}-24.5 \mathrm{IO}^{\prime} .
\end{aligned}
$$

For IOP, the IO' anomaly is scaled by the number of years between 1951 and the midpoint of the period used to create the climatology (1961-90), hence, $23.5 \mathrm{yr}$. For ION, using 1999, we obtain 24.5 yr. These two SST patterns reflect the changes of SST in the IWP between 1951 and 1999. Figure 2 illustrates the SST anomalies in the IWP domain. A prominent warming trend is evident in the tropical Indian Ocean and far western Pacific. The central intensity over the tropical Indian Ocean is about $0.5^{\circ} \mathrm{C}(23.5 \mathrm{yr})^{-1}$.

The experiments were integrated for $40 \mathrm{yr}$ of which the first $10 \mathrm{yr}$ were discarded as being the spinup stage. The analysis is done for the boreal summer season. The summertime mean was computed by averaging 3-month periods [June-August (JJA)] in each year. Finally, summertime means were calculated by averaging each JJA over the period of model experiment. Assuming that each year is statistically independent, this is equivalent for the anomaly experiments to an ensemble mean with 30 realizations.

The models that have been examined in this study include four AGCMs from the DYNAMITE project participants, which are as follows: the European Center for Research and Advanced Training in Scientific Computation (CERFACS) in France, the Max Planck Institute for Meteorology (MPI) in Germany, State Key Laboratory of Numerical Modeling for Atmospheric Sciences and Geophysical Fluid Dynamics (LASG)/ Institute of Atmospheric Physics (IAP) in China, and the Met Office's Hadley Centre for Climate Prediction and Research (UKMO) in the United Kingdom. In addition to the DYNAMITE partners, the climate variability working group of National Center for Atmospheric Research (NCAR) in the United States also carried out the same simulation using the NCAR Community Atmosphere Model, version 3 (CAM3). Thus, we have the outputs of five AGCMs. Table 1 shows a brief summary of each model. All AGCMs were forced by an identical SST field described above.

The verification data used in the present study consist of that from 1) the National Centers for Environmental Prediction (NCEP)-National Center for Atmospheric Research (hereafter NCEP) reanalysis data from 1958 to 1999 (Kalnay et al. 1996), and 2) the 40-yr European Centre for Medium-Range Weather Forecasts (ECMWF) Re-Analysis (ERA-40) dataset from 1958 to 1999 (Uppala et al. 2005). The observational geopotential height and wind field are obtained from the NCEP reanalysis and ERA-40. 
(a)

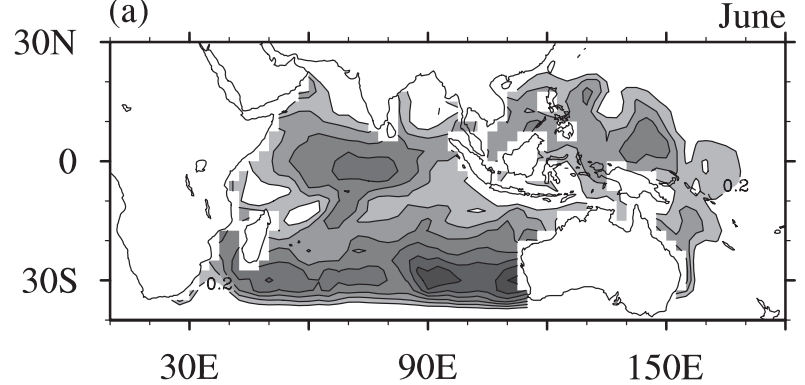

(b)

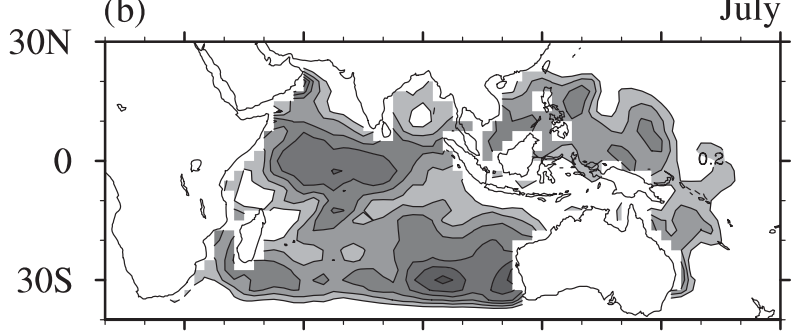

(c)

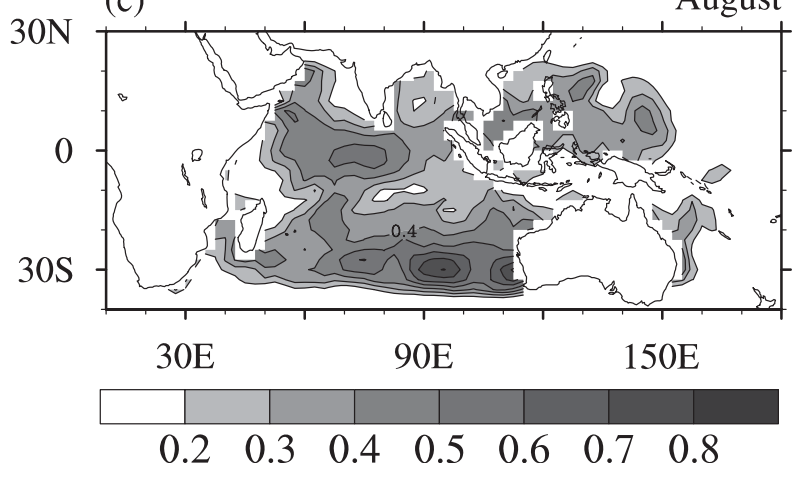

FIG. 2. Monthly mean distribution of the SST trends $\left[{ }^{\circ} \mathrm{C}\right.$ $(23.5 \mathrm{yr})^{-1}$ ] between 1951 and 1990 from the HadISST dataset: (a) June, (b) July, and (c) August. These SST anomalies were used to drive the AGCMs in IWP warming runs.

How can the position of the WPSH be measured? Although the vast subtropical anticyclone dominates both the low and middle troposphere of the North Pacific in boreal summer, it is termed as WPSH mainly in the middle troposphere. In the low troposphere the center of the anticyclone is located in the eastern Pacific, while in the middle troposphere the center of the anticyclone is located in the western Pacific and thus has a close connection to East Asian climate (Liu et al. 2001; Liu and $\mathrm{Wu}$ 2004). The WPSH is conventionally measured by the geopotential height at $500 \mathrm{hPa}$ (Z500) (e.g., Tao and Chen 1987; Ding 1994; Zhou and Li 2002; among many others). In our following discussions, we also use Z500 to describe the position of WPSH, along with part results at the other lower levels. We examine the results of each individual model but focus on the response of multimodel ensemble (MME).

\section{Results}

a. Response of WPSH to the prescribed IWP warming and cooling

To gain information about the decadal-scale shift of WPSH, we measure the WPSH by the contour line for $5870 \mathrm{gpm}$ of Z500. Figure 1 shows that there is a remarkable difference in the position and extent of WPSH between 1958-79 and 1980-99. Since the late 1970s, the WPSH has extended westward. Both the NCEP reanalysis and ERA-40 data show similar tendencies. During 1958-79, the mean position of the western edge of WPSH is located at $133.5^{\circ} \mathrm{E}\left(127.5^{\circ} \mathrm{E}\right)$ in the NCEP reanalysis (ERA-40). During 1980-99, the mean western edge of WPSH has shifted to $119.5^{\circ} \mathrm{E}\left(117.5^{\circ} \mathrm{E}\right)$ in the NCEP reanalysis (ERA-40). There are some discrepancies between the two reanalysis datasets in revealing the westward extension. The decadal shift of the western edge is $14^{\circ}$ in the NCEP reanalysis and $10^{\circ}$ in ERA-40. The interdecadal transition of the East Asian climate has also been manifested in other physical variables, including rain gauge data (e.g., Wang 2001; Hu et al. 2003; Yu et al. 2004; Yu and Zhou 2007), adding fidelity that the interdecadal shift of WPSH in the reanalysis data is real. Since the East Asian summer rainband is sensitive to the location and intensity of WPSH, this shift gives rise to an anticyclonic circulation anomaly over the region from the South China Sea to the western Pacific, and it results in prevailing southerlies over southern China (Gong and Ho 2002).

To verify whether the westward extension of WPSH resulted from the observed IWP warming, the response of WPSH to a warming (cooling) IWP was investigated in the coordinated experiments described in section 2. Because the climate mean intensities of WPSH simulated by five models are different, we delineate the WPSH by departures of Z500. The departure is from the zonal belt mean between $0^{\circ}$ and $40^{\circ} \mathrm{N}$. The results of the reanalysis and five AGCMs are shown in Fig. 3. The values of zonal belt mean height between $0^{\circ}$ and $40^{\circ} \mathrm{N}$ are marked at the right corner of each panel. The isoline of 10 -gpm height, which corresponds to 5870 -gpm isoline in the absolute geopotential height, arrives in $130^{\circ} \mathrm{E}$ in the NCEP reanalysis. The result derived from ERA40 is highly consistent (figure not shown). For brevity, we only present the results derived from NCEP reanalysis in the following discussions. In comparison with the reanalysis, the position of the 10 -gpm isoline extends westward in CAM3 and Grid Atmospheric Model of IAP/LASG (GAMIL) but retreats eastward in the fifth generation of the ECHAM general circulation model (ECHAM5), the third Hadley Centre atmospheric model (HadAM3), and Action de Recherche Petite Echelle 
TABLE 1. Description of five AGCMs.

\begin{tabular}{|c|c|c|c|c|}
\hline Institute & AGCM & Resolution & Convection scheme & Reference \\
\hline NCAR & CAM3 & T85L26 & $\begin{array}{l}\text { Deep convection is parameterized following } \\
\text { Zhang and McFarlane (1995); } \\
\text { shallow and upper-level convection } \\
\text { uses Hack (1994) }\end{array}$ & Boville et al. (2006) \\
\hline MPI & ECHAM5 & T63 L31 & $\begin{array}{l}\text { Tiedtke (1989), with modifications for } \\
\text { deep convection according to Nordeng (1994) }\end{array}$ & Roeckner et al. (2003) \\
\hline UKMO & HadAM3 & $\begin{array}{l}2.5^{\circ} \text { lat } \times 3.75^{\circ} \text { lon } \\
\quad \text { L19 }\end{array}$ & $\begin{array}{l}\text { Gregory and Rowntree (1990), with the } \\
\text { addition of convective downdrafts } \\
\text { (Gregory and Allen 1991) }\end{array}$ & Pope et al. (2000) \\
\hline IAP & GAMIL & $\begin{array}{l}2.8^{\circ} \text { lat } \times 2.8^{\circ} \text { lon } \\
\text { L26 }\end{array}$ & Zhang and McFarlane (1995) & Li et al. (2007) \\
\hline CERFACS & ARPEGE4.4 & T63 L31 & $\begin{array}{l}\text { Deep convection is represented by a mass flux } \\
\text { scheme with detrainment as proposed by } \\
\text { Bougeault (1985); stratiform and shallow } \\
\text { convection cloud formation is evaluated } \\
\text { via a statistical method described in } \\
\text { Ricard and Royer (1993) }\end{array}$ & Gibelin and Déqué (2002) \\
\hline
\end{tabular}

Grande Echelle (ARPEGE). The spread among the models in the climate mean states makes it difficult to measure the position of WPSH by using a same contour line such as $10 \mathrm{gpm}$. To handle the problem and make different model results comparable, we define the climatological isoline straddling the longitude of $130^{\circ} \mathrm{E}$ as the characteristic WPSH isoline. As shown in Fig. 3, there are differences in the strengths of the characteristic WPSH isoline among the models. For CAM3, the isoline used to delineate WPSH is $14 \mathrm{gpm}$ at $500 \mathrm{hPa}$. The characteristic WPSH isoline is zero gpm for ECHAM5, $5 \mathrm{gpm}$ for HadAM3, $20 \mathrm{gpm}$ for GAMIL, and $-10 \mathrm{gpm}$ for ARPEGE. The corresponding isoline for the NCEP reanalysis is $10 \mathrm{gpm}$.

The response of WPSH to a warming (cooling) IWP is depicted by the characteristic WPSH isoline. The results of five models are shown in Fig. 4. It is clear that the IWP warming (cooling) has led to a consistent westward extension (eastward retreat) of WPSH relative to its climate mean position. Qualitative comparison reveals that all AGCMs exhibit near-similar responses. Relative to the result of the ION experiment, the WPSH of the IOP experiment has a westward extension of $22^{\circ}$ in CAM $3,14^{\circ}$ in ECHAM5, $14^{\circ}$ in HadAM3, $18^{\circ}$ in GAMIL, and $13^{\circ}$ in ARPEGE. The response of CAM3 is the strongest, while that of ARPEGE is the weakest. Only the 30-yr mean condition is presented in Fig. 4. We have also examined the internal variability of each model by comparing the spread of characteristic WPSH isoline positions among the 30 realizations. The results indicate that both CAM3 and GAMIL models have a low level of internal variability compared to ARPEGE, HadAM3, and ECHAM5 (figures not shown). Because the physical package of GAMIL model is derived from the Com- munity Atmosphere Model, version 2 (CAM2) (Li et al. 2007), the similarity between these two models in terms of internal variability suggests an active role of model physics in producing the internal variability.

\section{b. The role of anomalous tropical convection located to the east of the date line}

Multimodel intercomparison indicates that the westward extension of WPSH might be partly due to the warming of IWP. What is the mechanism responsible for this robust response? In Fig. 5, the anomalies at $100 \mathrm{hPa}$ in the divergent wind component and velocity potential field are shown. Regions of low-level convergence over the IWP warmer water are mirrored in the upper troposphere by regions of divergence, as seen by the anomalous outflow at $100 \mathrm{hPa}$ in Fig. 5. Note that the upper-tropospheric convergence is located to the east of the date line, although a climatological SST was prescribed over there. This feature indicates the impact of IWP warming on the Walker circulation. Figure 5 indicates the above-normal convective activity centered on the equator at $120^{\circ} \mathrm{E}$ over the warmer water, but with evidence of reduced convective activity to the east of the date line.

In Fig. 6, the responses of JJA rainfall to IWP warming are shown. The upper-tropospheric divergent/convergent features in the velocity potential field have corresponding rainfall anomalies. The warming of IWP has caused rainfall to increase over most of the local basin and the Maritime Continent. Excessive rainfall develops over the Arabian Sea, Indian peninsula, and the Bay of Bengal. This is particularly the condition for the CAM3, GAMIL, and ECHAM5 models. The center of excessive rainfall is located to the south of Arabian Sea in HadAM3. In 

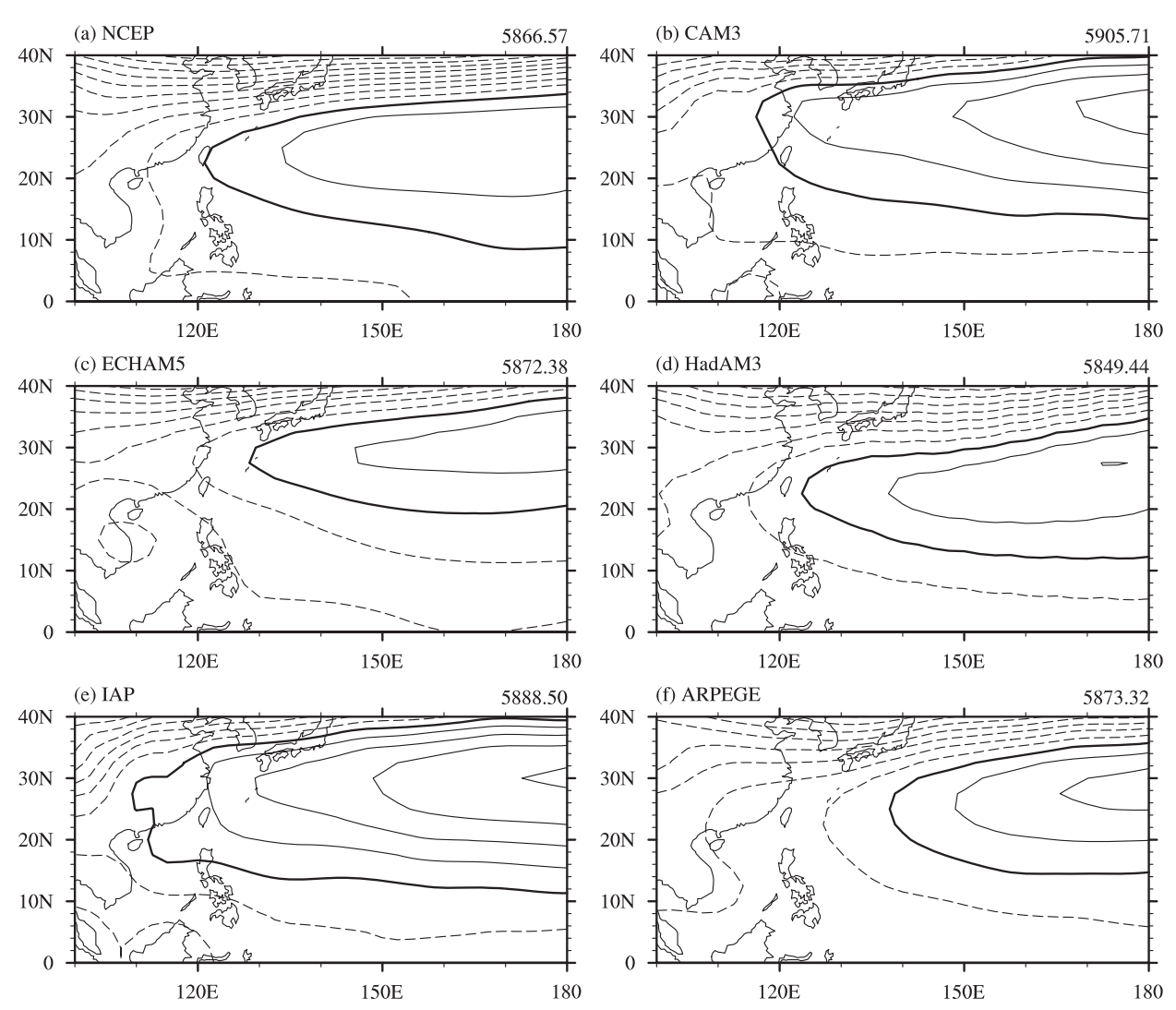

FIG. 3. Departures of JJA mean geopotential height at $500 \mathrm{hPa}$ in the (a) reanalysis and (b)-(f) control runs of AGCMs. The departure is calculated as the difference from the zonal mean between $0^{\circ}$ and $40^{\circ} \mathrm{N}$. The values of zonal mean between $0^{\circ}$ and $40^{\circ} \mathrm{N}$ are marked at the right corner (units: gpm). The name of AGCM is marked at the left corner. IAP refers to the GAMIL model. Contour interval is $10 \mathrm{gpm}$. The bold solid line corresponds to the isoline of zero.

addition to the positive centers located along the northern Indian Ocean, excessive rainfall also develops in the Maritime Continent, including the South China Sea. Note that the positive rainfall anomaly over the western Pacific in the ARPEGE model is stronger than the others, which is responsible for the slightly different subtropical anticyclone response discussed later. A further comparison of ARPEGE with the observational estimates indicates that the mean state for precipitation in ARPEGE over this area is not very realistic and might amplify the response (figures not shown here). In addition to the excessive rainfall anomalies associated with warmer water over the IWP, deficient rainfall anomalies are evident in the central and eastern tropical Pacific.

The excessive (deficient) rainfall anomalies indicate positive (negative) heating sources. The WPSH appears as the maximum in streamfunction of boreal summertime low-level circulation. Lu and Dong (2001) suggested that the WPSH at $850 \mathrm{hPa}$ is also stable and robust. To exhibit the relation between the WPSH variation and the anomalous heating, the horizontal streamfunction at 850
hPa for JJA based on the difference between the IOP and ION experiments for five AGCMs are presented in Fig. 7. In the vicinity of tropical heating implied by the precipitation anomalies, the streamfunction anomalies show a strong cyclonic couplet in both hemispheres straddling the equator over the tropical Indian Ocean. The close association between the largest precipitation anomalies and the streamfunction anomalies suggests that the anomalous latent heat release is likely to be forcing the circulation, which is consistent with the theory of Gill (1980). Inspection on JJA 850-hPa streamfunction (Fig. 7) reveals that nearly all models produce a cyclonic anomaly centralizing in the Arabian Sea, except for the ARPEGE model. The center of the cyclonic anomaly is located over the South China Sea rather than the Arabian Sea therein. The responses of streamfunction are consistent with the positions of precipitation anomalies, as shown in Fig. 6.

In addition to the Gill-type local response, another prominent feature of Fig. 7 is the North Pacific subtropical anticyclone. The close structural similarities 

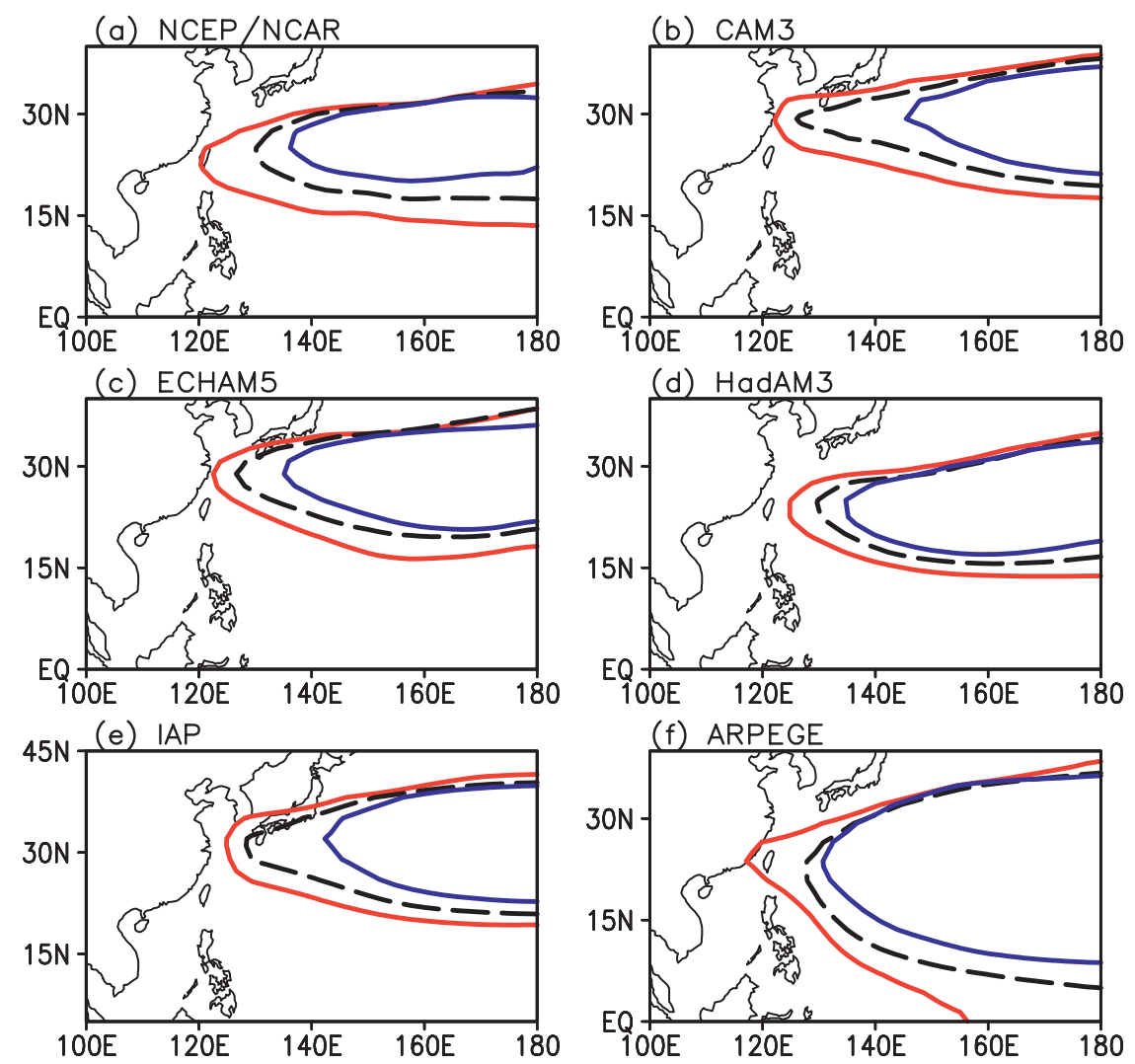

FIG. 4. (b)-(f) The positions of characteristic WPSH isoline at $500 \mathrm{hPa}$ in IWP warming (red) and cooling (blue) experiments and control runs (long-dashed black line) in the five AGCMs. The name of AGCM is marked at the left corner. (a) The model results are for a 30 -yr mean. IAP refers to the GAMIL model. The condition of the NCEP reanalysis is shown [1980-99 (red line), 1958-79 (blue line), and 1958-99 (long-dashed black line) mean].

among five AGCMs are very impressive. This anticyclonic response is consistent with the westward extension of WPSH shown in Fig. 4. What mechanisms govern the North Pacific response to IWP SST forcing? We suggest that it is due to the negative heating source associated with the deficient rainfall anomalies located to the east of the date line (cf. Fig. 6). The convection change in the central and eastern tropical Pacific result in the vigorous twin anticyclone gyres in the Pacific. Because there is no anomalous SST forcing in the Pacific, this should be a remote response to the extra heating in the regions of enhanced precipitation over the IWP region. The SST changes in the Indian Ocean and far western Pacific influence the Walker circulation, as evidenced by Fig. 5, with the subsequent changes in the tropical Pacific convective anomalies forcing an ENSO/Gill-like response that modulates the WPSH.

Examination on the vertical structure found that the intensity of North Pacific anticyclone gyre gradually decreases from the surface to the middle troposphere (figures not shown here). Given the strong response of
WPSH at $500 \mathrm{hPa}$, there should be a secondary reinforcing mechanism that favors the WPSH change. As to be discussed below, the monsoon diabatic heating mechanism proposed by Rodwell and Hoskins (1996) may work here.

\section{c. The role of monsoon diabatic heating}

Rodwell and Hoskins (2001) showed that the diabatic heating associated with the South Asian summer monsoon rainfall could affect the summer subtropical circulation over the North Pacific. To understand better how this mechanism might operate in our IWP SSTforcing experiments, we show in Fig. 8 the change of low-tropospheric flow associated with enhanced precipitation. The low over the Arabian Sea and Indian peninsula is consistent with the Gill-type response of streamfunction shown in Fig. 7. Over the North Pacific along the eastern Asian continent, there is a poleward anomalous flow between about $0^{\circ}-40^{\circ} \mathrm{N}$ and $90^{\circ}-135^{\circ} \mathrm{E}$. Over the Pacific, this poleward flow forms the western flank of the WPSH. Above analyses demonstrate that 

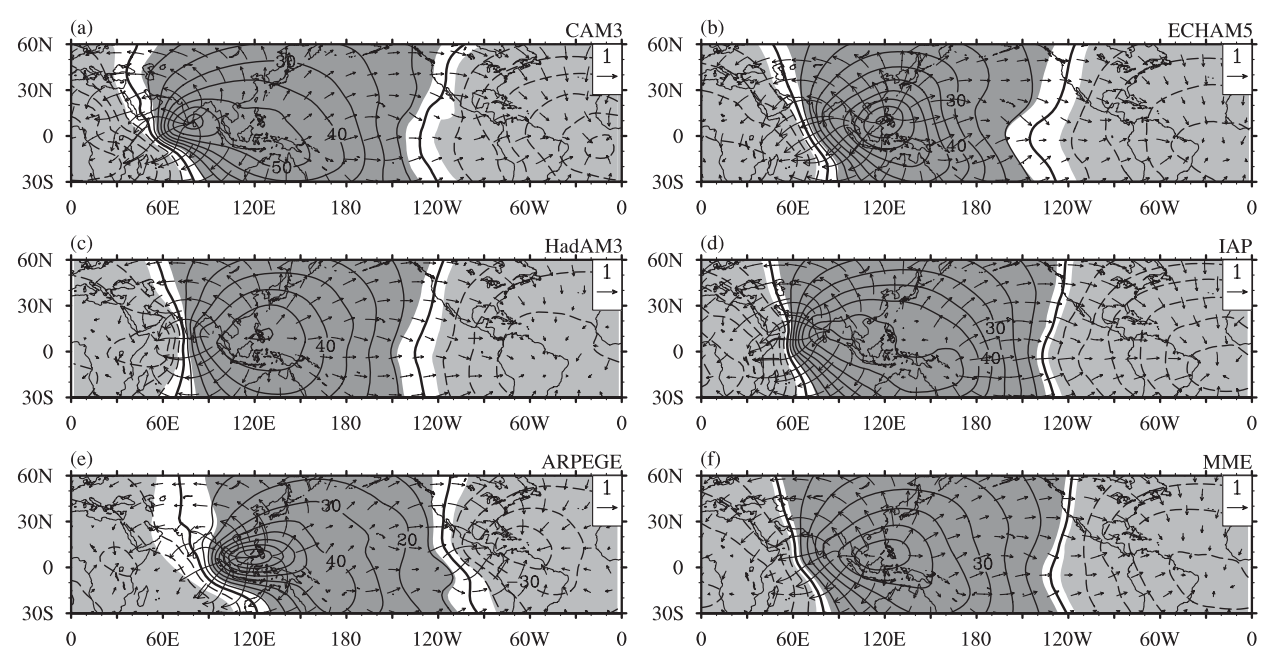

FIG. 5. 200-hPa velocity potential $\left(10^{6} \mathrm{~m}^{2} \mathrm{~s}^{-1}\right)$ and divergent component of the wind vectors $\left(\mathrm{m} \mathrm{s}^{-1}\right)$ for JJA mean based on the difference between the IWP warming and cooling experiments. Shaded regions are statistically significant at the $1 \%$ level according to the Student's $t$ test. Vectors are the divergent components of the wind field: (a) CAM3, (b) ECHAM, (c) HadAM3, (d) IAP, (e) ARPEGE, and (f) MME.

the anticyclone gyre driven by negative heating source over the central and eastern tropical Pacific is the primary reason for this poleward flow. The secondary reinforcing agent may come from the Sverdrup vorticity balance.

The poleward anomalous flow is associated with the Sverdrup vorticity balance, which is expressed as

$$
\beta v \approx f \frac{\partial \omega}{\partial p}
$$

where $v$ is meridional wind, $\omega$ is the vertical velocity, $f$ is the Coriolis parameter, and $\beta$ is its meridional gradient (Rodwell and Hoskins 2001; Hoskins and Wang 2006). The Sverdrup balance can also be expressed in other forms to emphasize the importance of the vertical distribution of heating (Wu et al. 1999).

In agreement with Sverdrup vorticity balance of the steady flow, strong poleward flow at the low level should be seen below the maximum ascent. This relationship is
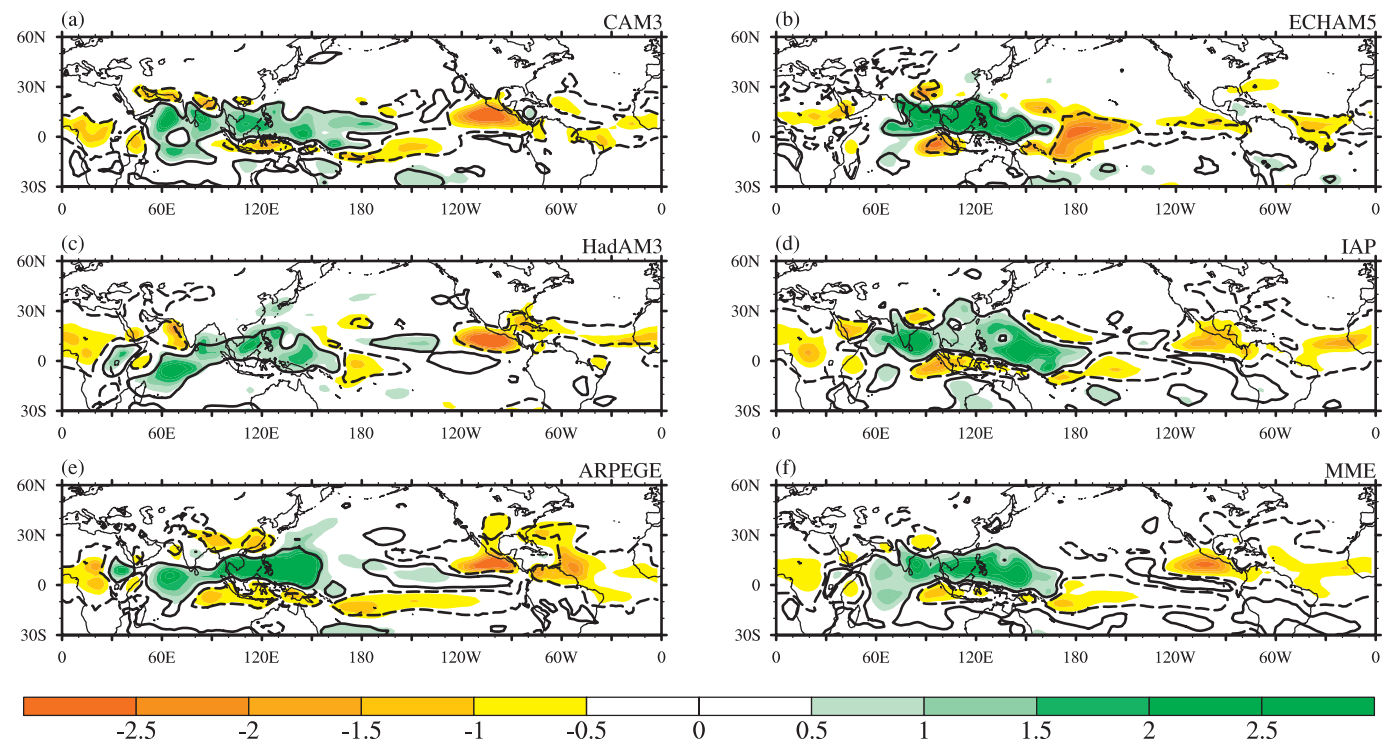

$-2$

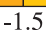

$$
-1
$$

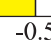

FIG. 6. Composite of JJA precipitation differences $\left(\mathrm{mm} \mathrm{day}^{-1}\right)$ between the IWP warming and IWP cooling experiments: (a) CAM3, (b) ECHAM, (c) HadAM3, (d) IAP, (e) ARPEGE, and (f) MME. IAP refers to the GAMIL model. Values statistically significant at the $1 \%$ level according to the Student's $t$ test are encircled by black lines. 

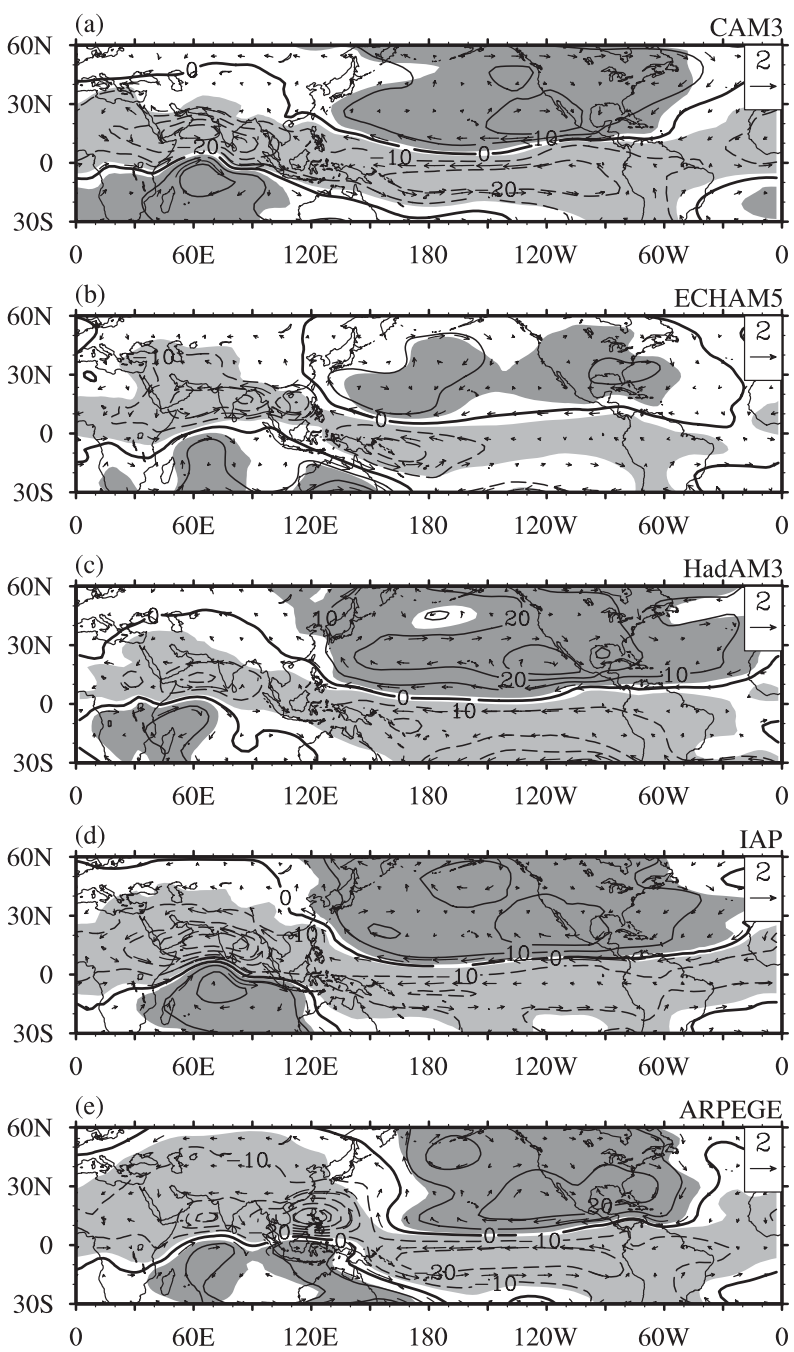

FIG. 7. Horizontal streamfunction at $850 \mathrm{hPa}$ for JJA based on the difference between the IWP warming and cooling experiments $\left(10^{6} \mathrm{~m}^{2} \mathrm{~s}^{-1}\right)$. Shaded regions are statistically significant at the $1 \%$ level according to the Student's $t$ test. Vectors are the nondivergent components of the wind field $\left(\mathrm{m} \mathrm{s}^{-1}\right)$. (a) CAM3, (b) ECHAM, (c) HadAM3, (d) IAP, and (e) ARPEGE. IAP refers to the GAMIL model.

well captured by the model results. The MME rainfall anomaly pattern, the longitude-height plots of vertical velocity gradient $\partial \omega / \partial p$, and the meridional wind for the $0^{\circ}-20^{\circ} \mathrm{N}$ average, the latitude-height cross section of meridional wind, are shown in Fig. 9. There is strong upward motion above the heating region. A positive gradient $\partial \omega / \partial p$ develops below the maximum upward motion. The strongest vertical velocity gradient $\partial \omega / \partial p$ is located around $600-700 \mathrm{hPa}$ along $120^{\circ} \mathrm{E}$ (Fig. 9b). Following the strong ascent gradient, poleward flows to the east of the heating center are evident in the MME responses. Corresponding to the three anomalous rainfall centers located in the southern Arabian Sea, the Bay of
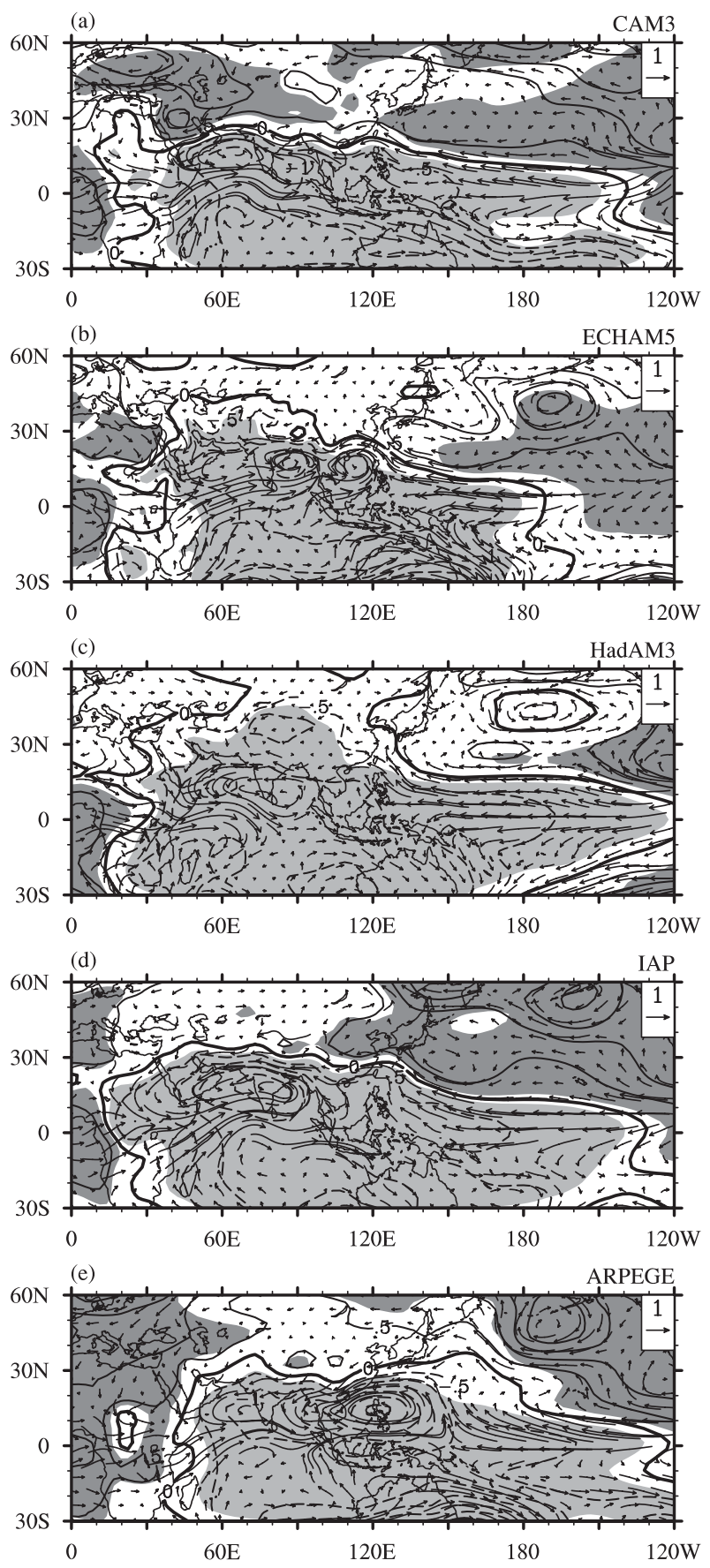

FIG. 8. Surface pressure $(\mathrm{Pa})$ and 850 -hPa horizontal wind anomalies $\left(\mathrm{m} \mathrm{s}^{-1}\right)$ calculated as the difference between the IWP warming and cooling experiments. Positive contours are solid and negative contours are dashed. (a) CAM3, (b) ECHAM, (c) HadAM3, (d) IAP, (e) ARPEGE. Shaded regions are statistically significant at the 5\% level according to the Student's $t$ test. IAP refers to the GAMIL model.

Bengal, and the South China Sea, respectively, strong ascent and the associated vertical gradients are evident, straddling $65^{\circ}, 80^{\circ}$, and $120^{\circ} \mathrm{E}$, respectively. The gradient of upward motions over $120^{\circ} \mathrm{E}$ is the strongest and 

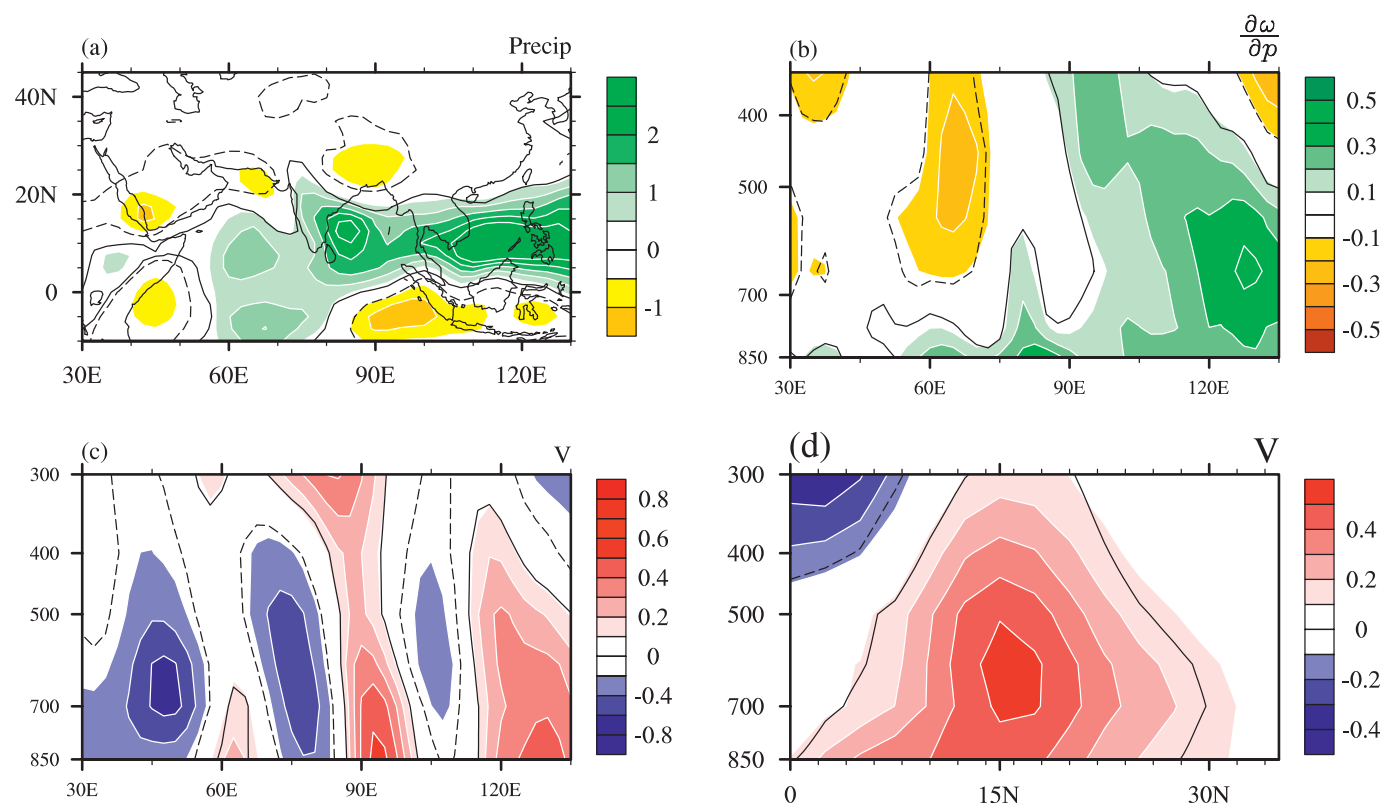

FIG. 9. Anomalous JJA (a) precipitation $\left(\mathrm{mm}^{\mathrm{day}}{ }^{-1}\right)$, (b) longitude-height cross section of vertical velocity gradient $\partial \omega / \partial p\left(10^{-6} \mathrm{~s}^{-1}\right)$, (c) longitude-height cross section of meridional wind $\left(\mathrm{m} \mathrm{s}^{-1}\right)$, and (d) latitude-height cross section of meridional wind $\left(\mathrm{m} \mathrm{s}^{-1}\right)$. The anomalies were calculated as the difference between the IWP warming and IWP cooling experiments. All results are for a multimodel ensemble. The anomalies are shown as $0^{\circ}-20^{\circ} \mathrm{N}$ average in (b) and (c), and as a $115^{\circ}-130^{\circ} \mathrm{E}$ average in (d). Values statistically significant at the $1 \%$ level according to the Student's $t$ test are encircled by black lines.

penetrates upward to $400 \mathrm{hPa}$ (Fig. 9b). Associated with the positive vertical gradients of upward motion, poleward anomalous meridional winds prevail (Fig. 9c). Along $120^{\circ} \mathrm{E}$, where meridional wind anomalies develop, we show the latitude-height cross section of meridional wind anomalies in Fig. 9d. The meridional wind anomalies straddling $120^{\circ} \mathrm{E}$ extend northward up to $30^{\circ} \mathrm{N}$. The core of the meridional wind anomaly is located around $600 \mathrm{hPa}$, which matches that of the vertical velocity gradient shown in Fig. 9b, indicating a good correspondence between the maximum vertical velocity gradient and the maximum meridional wind. This situation strictly matches the Sverdrup vorticity balance. Hence, the Sverdrup balance works well in the model results. The poleward meridional wind straddling $120^{\circ} \mathrm{E}$ corresponds to the western flank of WPSH. The changes of meridional wind are beneficial to an intensified western flank of WPSH.

We have also performed a model-by-model comparison, although there are differences in the positions of upward motion, the maximum vertical velocity gradient, and the associated poleward flows in the middle and low troposphere; all five models' responses support the mechanism that the condensational heating induces a robust ascent, along with a positive vertical velocity gradient below the maximum ascent, which further leads to intensified poleward flows in the low troposphere resulting from the Sverdrup vorticity balance (figures not shown). Hence, the formation of western flank of the anomalous WPSH can be partly explained in terms of the Sverdrup vorticity balance, as a secondary reinforcing mechanism.

In addition to the poleward meridional flow, strengthened easterlies in the equatorial Pacific are evident in all models' responses (see Figs. 7-8). This anomalous easterly forms the southern flank of the WPSH. The anticyclonic gyre generated by the negative heat source over the central and eastern tropical Pacific dominates the anomalous easterlies, as discussed in the last section. The condensational monsoon heating may serve as a secondary mechanism. These wind anomalies show close similarities to the analytical results of Gill (1980). They are identifiable with the equatorial Kelvin wave solution to South Asian monsoon heating; that is, the flow pattern to the east of the heating region is due to the eastward propagation of the Kelvin waves, and thus, the winds are easterlies toward the heat source and tend to be parallel to the equator (Hoskins and Wang 2006). Therefore, the intensified summertime low-level equatorial flank of the WPSH can also be partly interpreted as a Kelvin wave response to the intensified South Asian monsoon heat source. The stronger WPSH easterly is 
(a) NCEP/NCAR

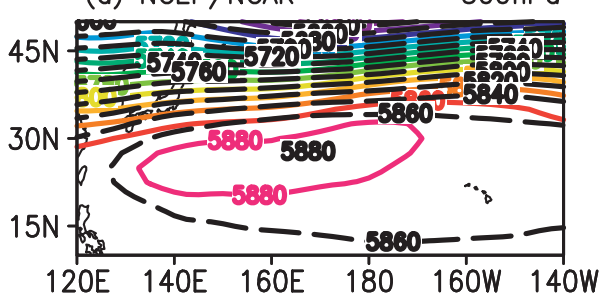

(b) NCEP/NCAR

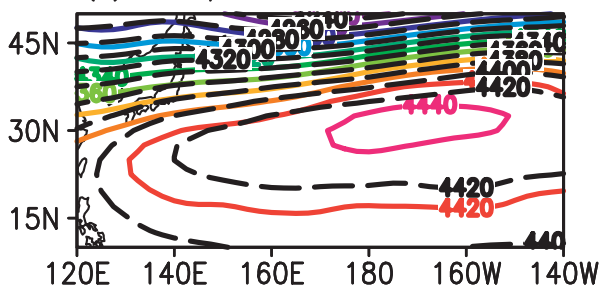

(e) MME

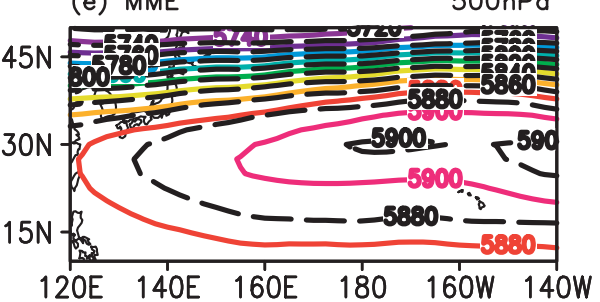

(f) $M M E$

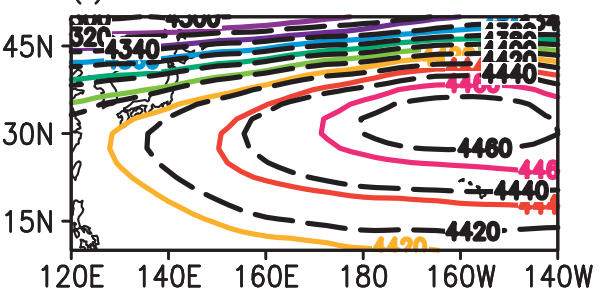

(c) NCEP/NCAR

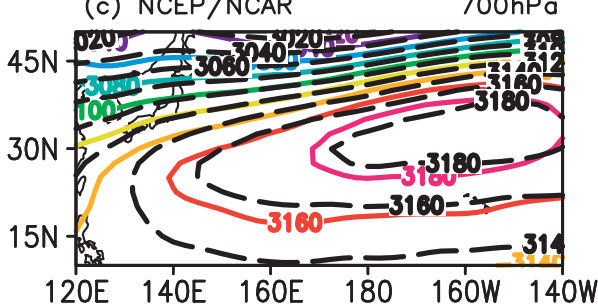

(g) MME

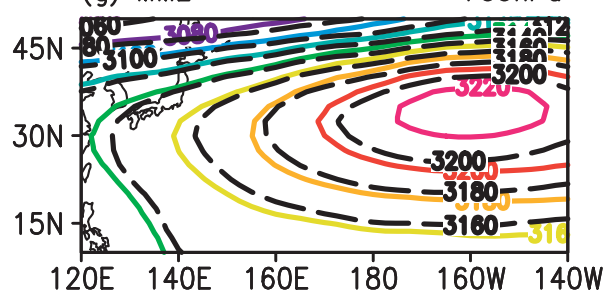

(d) NCEP/NCAR

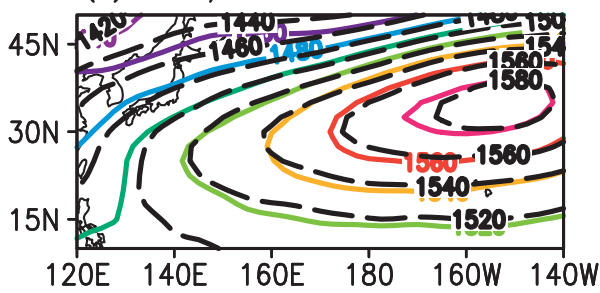

(h) MME

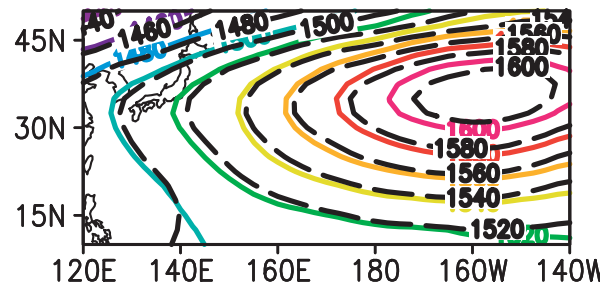

FIG. 10. Spatial distributions of JJA mean geopotential height (gpm) at (from top to bottom) 500, 600,700 , and $850 \mathrm{hPa}$ from the (left) reanalysis and (right) multimodel ensemble. The results of IWP warming (cooling) experiment are shown in color (long-dashed black) in the right column. The results of NCEP reanalysis are shown in color (long-dashed black) for 1980-99 (1958-79) mean in the left column.

primarily the southern part of the anticyclonic gyre driven by the negative heating source over the central and eastern tropical Pacific, and secondarily a response to the increased convective heating associated with the IWP warming.

In above discussions, we either describe the westward extension of WPSH by using Z500 conventionally or analyzing the model results at $850 \mathrm{hPa}$, as in previous modeling studies. This does not mean that the changes of WPSH at the other levels of the middle-low troposphere are not significant. Figure 9 has already shown that the models' responses are robust from $400 \mathrm{hPa}$ to the surface (cf. Figs. 9b-d). In Fig. 10, we present the changes of geopotential height from 500 to $850 \mathrm{hPa}$ for both the reanalysis and the MME simulation. It is clear that in the reanalysis, the interdecadal scale westward extension of WPSH is not a unique feature at $500 \mathrm{hPa}$, but has occurred throughout the whole middle-low troposphere (Figs. 10a-d). In the MME numerical simulation, a warming IWP has led to a westward extension of WPSH from $500 \mathrm{hPa}$ to the surface (Figs. 10e-h). Above mechanism analyses concerning both the primary negative 
heating in the central and eastern tropical Pacific and the secondary monsoon diabatic heating should also apply to the other levels of middle-low troposphere.

\section{d. The upper-tropospheric response}

In addition to the WPSH in the middle and lower troposphere, another persistent subtropical anticyclone controlling the free atmosphere over Asia during boreal summer is the South Asian anticyclone, termed the "South Asian high" ("SAH"), in the upper troposphere over the region to the north of the Bay of Bengal (Tao and Chen 1987). The climate impact of IWP warming may also be manifested in the SAH. In Gill's model, the vertical structure of the tropical atmosphere is described by a single baroclinic mode, such that circulation anomalies in the upper troposphere are opposite to those in the lower troposphere (Gill 1980; Sutton and Hodson 2007). The 100-hPa streamfunction anomalies between IOP and ION experiments are presented in Fig. 11. The patterns of twin upper-level anticyclones over the warming IWP region in the CMA3, ECHAM5, HadAM3, and GAMIL models resemble that predicted by Gill's theory. The twin anticyclone simulated by ARPEGE model is more significant at a level higher than $100 \mathrm{hPa}$ (figure not shown). In addition, the vigorous twin upper-level cyclones straddling the equator in the Pacific primarily come from the negative heating source forced by convection changes in the central and eastern tropical Pacific, as discussed in section $3 b$.

Previous studies demonstrate that the latent heating released by the South Asian monsoon rainfall is beneficial to the formation of SAH (Liu et al. 2001; Yang et al. 2007). According to Eq. (3), above the maximum ascent, the Sverdrup balance requires an equatorward flow. This is evident in Figs. 11a-d. An examination on the vertical cross section also demonstrates that the core of maximum equatorial wind at upper troposphere matches that of vertical velocity gradient $\partial \omega / \partial p$ (figures not shown). The meridional wind component of SAH can be partly explained by the Sverdrup balance, as a secondary mechanism to the direct Gill-type response.

In observation, the SAH is usually measured by the contour line of $16800 \mathrm{gpm}$ of the 100-hPa geopotential height (Zhang et al. 2000). Similar as the condition of WPSH at $500 \mathrm{hPa}$, the climate mean intensities of SAH simulated by five models are different; we delineate the $\mathrm{SAH}$ by the departures of the $100-\mathrm{hPa}$ geopotential height. The departure is from the zonal belt mean between $0^{\circ}$ and $60^{\circ} \mathrm{N}$. The results of the reanalysis and five AGCMs are shown in Fig. 12. The simulated SAH differs from the reanalysis in both the intensity and coverage. The center of SAH shifts westward in CAM3 and northward in the GAMIL model. The central intensity
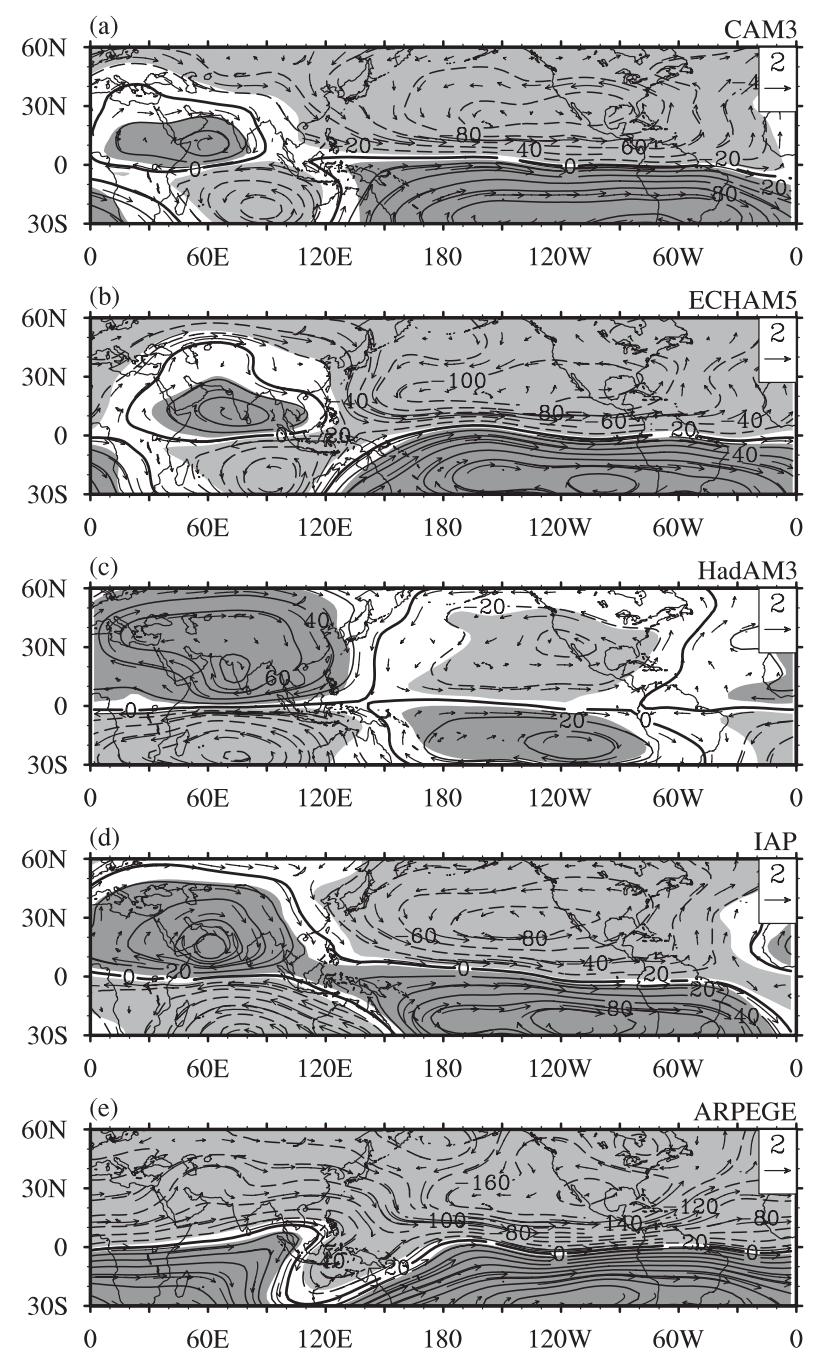

FIG. 11. Horizontal streamfunction at $100 \mathrm{hPa}$ for JJA mean based on the difference between the IWP warming and IWP cooling experiments $\left(10^{6} \mathrm{~m}^{2} \mathrm{~s}^{-1}\right)$. Shaded regions are statistically significant at the $1 \%$ level according to the Student's $t$ test. Vectors are the nondivergent components of the wind field $\left(\mathrm{m} \mathrm{s}^{-1}\right)$. (a) CAM3, (b) ECHAM, (c) HadAM3, (d) IAP, and (e) ARPEGE. IAP refers to the GAMIL model.

of SAH is weaker than the reanalysis in nearly all models except for CAM3. The coverage of the 200-gpm isoline is larger than the reanalysis in all five models. In the following discussion, we define the contour line of $200 \mathrm{gpm}$ as the characteristic SAH isoline and make comparisons between IWP warming and IWP cooling experiments for each individual model.

Associated with the interdecadal scale transition of the East Asian climate since the late 1970s, the SAH has experienced an expansion in zonal coverage (Zhang et al. 2000). This intensified SAH is evident in Fig. 13a. To verify whether the SAH expansion is partly due to the IWP warming, the response of SAH to a warming 

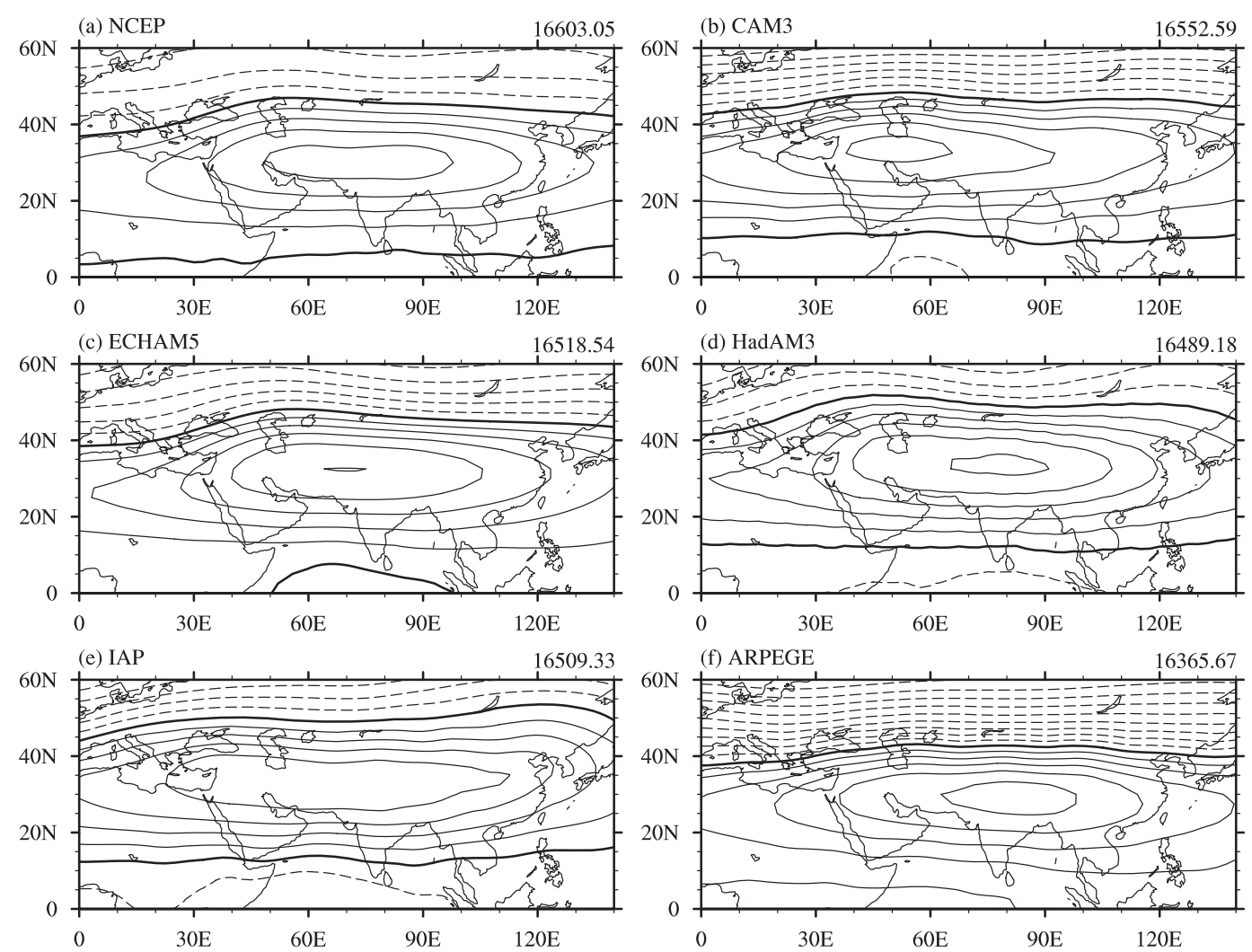

FIG. 12. Departures of JJA mean geopotential height at $100 \mathrm{hPa}$ in the (a) reanalysis and (b)-(f) control runs of AGCMs. The departure is calculated as the difference from the zonal mean between $0^{\circ}$ and $60^{\circ} \mathrm{N}$. The values of zonal mean between $0^{\circ}$ and $60^{\circ} \mathrm{N}$ are marked at the right corner $(\mathrm{gpm})$. The name of AGCM is marked at the left corner. Contour interval is $50 \mathrm{gpm}$. The bold solid line corresponds to the isoline of zero. IAP refers to the GAMIL model.

(cooling) IWP is depicted by the characteristic SAH isoline. The results of five models are presented in Figs. 13b-f, respectively. The IWP warming (cooling) has led to a consistent zonal expansion (shrinkage) of SAH relative to the climate mean position. Given the fact that all AGCMs exhibit similar responses, the IWP warming is contributive to the expansion of SAH since the late 1970s.

\section{Discussion}

In nature, there is an interaction between the Asian monsoon and WPSH in the sense that either one would be different without the other. This study only addresses how the South Asian monsoon heating affects the summertime WPSH and not vice versa. The results reveal a qualitative agreement of five AGCMs in producing the westward extension of WPSH owing to the IWP warming. The results indicate that both the negative heating source over the central and eastern tropical Pacific and the direct condensational heat release accompanying the increased South Asian monsoon rains are contributive to the westward extension of WPSH. The warming of IWP has caused an increasing of monsoon rains over most parts of the local basin in all five models; further inspections on the spatial pattern and intensity of rainfall anomalies simulated by five AGCMs still find some differences (Fig. 6). The local maximum of rainfall anomalies reflects the center of diabatic heating. Although all AGCMs employed an identical SST forcing, their rainfall responses are not exactly identical. The difference of diabatic heating that accompanies the increased monsoon rains accounts for the discrepancies among five models in producing some regional features of circulation responses (Figs. 7-8). Why does an identical SST forcing lead to slightly different model responses? This discrepancy is very likely to be at the origin of differences between models. Although an identical SST forcing was employed, there are spreads among the precipitation responses of five AGCMs resulting from different model sensitivities.

It is important to note that the East Asian summer climate is extremely sensitive to both the western boundary and ridge line of the WPSH. Any bias of the climate models in simulating the climate mean position of WPSH 
(a) NCEP/NCAR

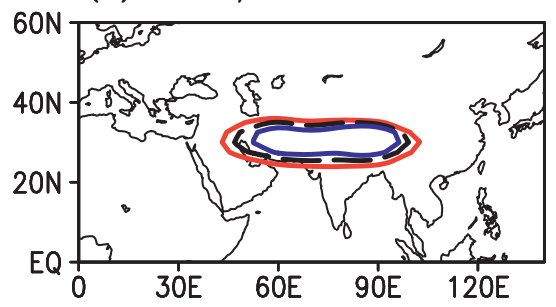

(c) ECHAM5

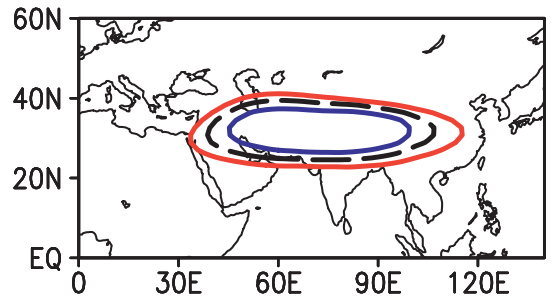

(e) IAP

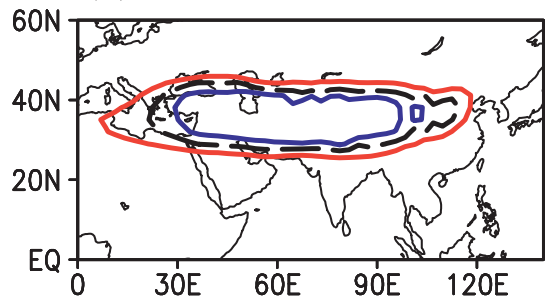

(b) CAM3

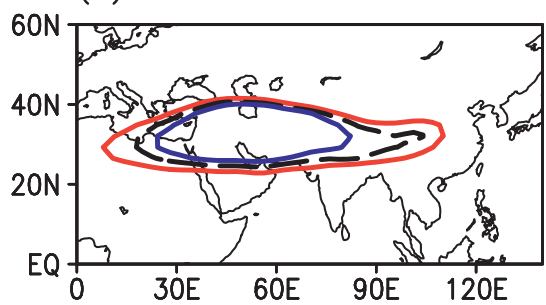

(d) HadAM3

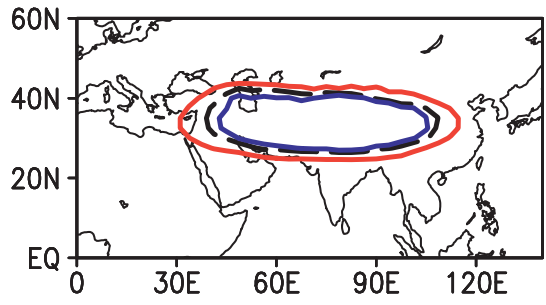

(f) ARPEGE

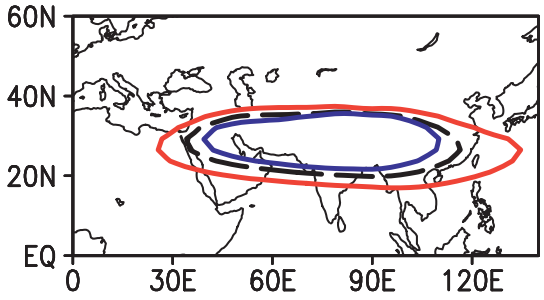

FIG. 13. (b)-(f) Coverage of JJA mean characteristic SAH isoline at $100 \mathrm{hPa}$ in IWP warming (red) and cooling (blue) experiments and control runs (long-dashed black line) in the five AGCMs. The name of AGCM is marked at the left corner. IAP refers to the GAMIL model. The model results are for the 30-yr mean. (a) The condition of NCEP reanalysis is shown [1980-99 (red line), 1958-79 (blue line), and 1958-99 (long-dashed black line) mean].

would lead to a bias in monsoon circulations and the associated mei-yu front. Unfortunately, most AGCMs analyzed here suffer from this kind of bias. For example, the climatological mean positions of the ridge line for WPSH simulated by the CAM3, ECHAM5, and GAMIL models are about $5^{\circ}-6^{\circ}$ north of the reanalysis (Figs. 3-4). The western edges of climatological WPSH simulated by the CAM3 and GAMIL models extend to the west of the reanalysis (Figs. 3-4). These biases make it difficult to compare the simulated wind anomaly over the East Asian continent with that of the reanalysis.

The limitations of our experimental setup should be acknowledged. As shown in Fig. 2, the Philippine Sea has been included as part of the IWP region. Previous studies found a relationship between the zonal extent of WPSH and the intensity of atmospheric convection over the Philippine Sea. For example, stronger (weaker) convection over the Philippine Sea is associated with more eastward retreat (westward extension) of WPSH (Lu 2001). Numerical model experiments also show that the suppressed convection caused by colder SST in the
Philippine Sea results in a westward extension of WPSH (Lu and Dong 2001). Although this relationship is based on studies of the interannual variability of WPSH, it implies that the prescribed warming trend in the Philippine Sea might have a negative contribution to the westward extension of WPSH. This hypothesis should be verified by numerical model experiments that exclude the SST anomalies in the western Pacific warm pool region shown in Fig. 2. A set of such coordinated multimodel experiments are being undertaken as part of the European Union's Sixth Framework Programme (i.e., DYNAMITE).

Another potential limitation is the use of a prescribed SST boundary forcing in the Asian-Australian monsoon domain. Recent research suggests that the prediction/ simulation of an Asian-Australian summer monsoon requires taking into account local monsoon-warm pool ocean interactions (Wang et al. 2005; Wu and Kirtman 2005; Krishna Kumar et al. 2005; Zhou et al. 2008, 2009). In our experiments, the atmosphere is forced to respond passively to the specified SSTs, while in nature the SSTs 
are also partly forced by the atmosphere (Wang et al. 2005), suggesting that the role of IWP SST forcing might be exaggerated in our experiments.

\section{Summary}

The WPSH plays a major role in East Asian climate. Previous observational analyses found that the WPSH has extended westward since the late 1970s, contributing to the interdecadal transition of East Asian climate. The cause for the westward extension of WPSH is addressed by employing an idealized SST-forcing AGCM approach. Coordinated by a European Union's Sixth Framework Programme "Understanding the Dynamics of the Coupled Climate System" ("DYNAMITE"), we carried out experiments in which five AGCMs were forced by an identical idealized SST pattern representative of the IWP warming. The results of numerical experiments indicate that both the negative heating in the central and eastern tropical Pacific and the increased convective heating in the equatorial Indian Ocean/ Maritime Continent, associated with a warming of IWP, have contributed to the westward extension of WPSH since the late 1970s. The major results are summarized as follows:

1) Responses of WPSH to IWP warming exhibit a westward extension in all five AGCMs. The magnitude of the westward extension is model dependent, ranging from $13^{\circ}$ in ARPEGE to $22^{\circ}$ in CAM3. The extension in the MME is $16.2^{\circ}$, which is slightly stronger than the average of the data of the two reanalysis $\left(12.0^{\circ}\right)$.

2) The IWP warming has caused excessive rainfall over most parts of the IWP basin in all AGCM responses. Excessive rainfall develops over the Arabian Sea, the Indian peninsula, the Bay of Bengal, and the Maritime Continent, including the South China Sea, indicating an intensified convective heating. The SST changes in the IWP influence the Walker circulation and result in deficient rainfall in the central and eastern tropical Pacific, signifying a negative heating source over there.

3) The negative heating source associated with the tropical Pacific convective anomalies forces an ENSO/ Gill-like response that modulates the WPSH. The resulted anticyclonic gyre in the North Pacific is favorable to the westward extension of WPSH and is regarded as the primary forcing mechanism.

4) The monsoon diabatic heating mechanism proposed by Rodwell and Hoskins (1996) plays a secondary reinforcing role in the westward extension of WPSH. The low-level equatorial flank of WPSH is inter- preted as a Kelvin response to the monsoon condensational heating, while the intensified poleward flow along the western flank of WPSH is in accord with Sverdrup vorticity balance.

5) The climate impact of IWP warming is also evident in South Asian high in the upper troposphere. The increased convective heating associated with IWP warming results in an expansion of $\mathrm{SAH}$, as seen in the reanalysis. Both the primary Gill-type response and the secondary Sverdrup balance are in favor of the expansion.

Acknowledgments. This work was jointly supported by the Major State Basic Research Development Program of China (973) under Grant 2006CB403603, the National Natural Science Foundation of China under Grants 40625014, 40523001, and 40628006, and the EU's Sixth Framework Programme under Contract 003903GOCE (DYNAMITE).

\section{REFERENCES}

Bergman, J. W., and H. H. Hendon, 2000: The impact of clouds on the seasonal cycle of radiative heating over the Pacific. J. Atmos. Sci., 57, 545-566.

Bougeault, P., 1985: A simple parameterization of the large-scale effects of cumulus convection. Mon. Wea. Rev., 113, 21082121.

Boville, B. A., P. J. Rasch, J. J. Hack, and J. R. McCaa, 2006: Representation of clouds and precipitation processes in the Community Atmosphere Model version 3 (CAM3). J. Climate, 19, 2184-2198.

Chang, C.-P., Y. Zhang, and T. Li, 2000a: Interannual and interdecadal variations of the East Asian summer monsoon and tropical Pacific SSTs. Part I: Role of the subtropical ridge. J. Climate, 13, 4310-4325.

,-- , and $-2000 \mathrm{~b}$ : Interannual and interdecadal variations of the East Asian summer monsoon and tropical Pacific SSTs. Part II: Meridional structure of the monsoon. J. Climate, 13, 4326-4340.

Chen, P., M. P. Hoerling, and R. M. Dole, 2001: The origin of the subtropical anticyclones. J. Atmos. Sci., 58, 1827-1835.

Deser, C., and A. S. Phillips, 2006: Simulation of the 1976/77 climate transition over the North Pacific: Sensitivity to tropical forcing. J. Climate, 19, 6170-6180.

Ding, Y. H., 1994: The summer monsoon in East Asia. Monsoons over China, Kluwer Academic, 1-9.

Gibelin, A.-L., and M. Déqué, 2002: Anthropogenic climate change over the Mediterranean region simulated by a global variable resolution model. Climate Dyn., 20, 327-339.

Gill, A. E., 1980: Some simple solutions for heat induced tropical circulation. Quart. J. Roy. Meteor. Soc., 106, 447-462.

Gong, D.-Y., and C.-H. Ho, 2002: Shift in the summer rainfall over the Yangtze River valley in the late 1970s. Geophys. Res. Lett., 29, 1436, doi:10.1029/2001GL014523.

Gregory, D., and P. R. Rowntree, 1990: A mass flux convection scheme with representation of cloud ensemble characteristics and stability-dependent closure. Mon. Wea. Rev., 118, 1483-1506. 
- , and S. Allen, 1991: The effect of convective scale downdraughts upon NWP and climate simulations. Preprints, Ninth Conf. on Numerical Weather Prediction, Denver, CO, Amer. Meteor. Soc., 122-123.

Hack, J. J., 1994: Parameterization of moist convection in the National Center for Atmospheric Research Community Climate Model (CCM2). J. Geophys. Res, 99, 5551-5568.

He, X.-Z., and D.-Y. Gong, 2002: Interdecadal change in western Pacific subtropical high and climatic effects. J. Geogr. Sci., 12, 202-209.

Hoerling, M. P., J. W. Hurrell, and T. Xu, 2001: Tropical origins for recent North Atlantic climate change. Science, 292, 90-92.

Hoskins, B. J., 1996: On the existence and strength of the summer subtropical anticyclone. Bull. Amer. Meteor. Soc., 77, 12871292.

— Asian Monsoon, B. Wang Ed., Springer, 357-415.

Hu, Z.-Z., 1997: Interdecadal variability of summer climate over East Asia and its association with $500 \mathrm{hPa}$ height and global sea surface temperature. J. Geophys. Res., 102, 19 403-19 412.

_ S. Yang, and R. Wu, 2003: Long-term climate variations in China and global warming signals. J. Geophys. Res., 108, 4614, doi:10.1029/2003JD003651.

Huang, R., and Y. Wu, 1989: The influence of ENSO on the summer climate change in China and its mechanism. $A d v$. Atmos. Sci., 6, 21-32.

— , and F. Y. Sun, 1992: Impact of the tropical western Pacific on the East Asian summer monsoon. J. Meteor. Soc. Japan, 70, 243-256.

Huang, S. S., 1963: Longitudinal movement of the subtropical anticyclone and its prediction (in Chinese). Acta Meteor. Sin., 33, 320-332.

_ and some associated aspects of the general circulation of atmosphere (in Chinese). Acta Meteor. Sin., 31, 339-359.

Krishna Kumar, K., M. Hoerling, and B. Rajagopalan, 2005: Advancing dynamical prediction of Indian monsoon rainfall. Geophys. Res. Lett., 32, L08704, doi:10.1029/2004GL021979.

Kurihara, K., 1989: A climatological study on the relationship between the Japanese summer weather and the subtropical high in the western northern Pacific. Geophys. Mag., 43, 45-104.

— around Japan and its association with Rossby wave-like propagations over the North Pacific: Analysis of August 1984. J. Meteor. Soc. Japan, 65, 237-246.

Lau, K.-M., and M.-T. Li, 1984: The monsoon over East Asia and its global association-A survey. Bull. Amer. Meteor. Soc., 65, $116-125$

Li, J., R. Yu, T. Zhou, and B. Wang, 2005: Why is there an early spring cooling shift downstream of the Tibetan Plateau? $J$. Climate, 18, 4660-4668.

Li, L., B. Wang, and T. Zhou, 2007: Contributions of natural and anthropogenic forcings to the summer cooling over eastern China: An AGCM study. Geophys. Res. Lett., 34, L18807, doi:10.1029/2007GL030541.

Liu, Y., and G. Wu, 2004: Progress in the study on the formation of the summertime subtropical anticyclone. Adv. Atmos. Sci., 21, $322-342$.

, - H. Liu, and P. Liu, 2001: Dynamical effects of condensation heating on the subtropical anticyclones in the Eastern Hemisphere. Climate Dyn., 17, 327-338.
- - — - and R. Ren, 2004: Relationship between the subtropical anticyclone and diabatic heating. J. Climate, 17, 682-698.

Lu, R., 2001: Interannual variability of the summertime North Pacific subtropical high and its relation to atmospheric convection over the warm pool. J. Meteor. Soc. Japan, 79, 771-783.

— , and B. W. Dong, 2001: Westward extension of North Pacific subtropical high in summer. J. Meteor. Soc. Japan, 79, 12291241.

Miyasaka, T., and H. Nakamura, 2005: Structure and formation mechanisms of the Northern Hemisphere summertime subtropical highs. J. Climate, 18, 5046-5065.

Ninomiya, K., and C. Kobayashi, 1999: Precipitation and moisture balance of the Asian summer monsoon in 1991. Part II: Moisture transport and moisture balance. J. Meteor. Soc. Japan, 77, 77-99.

Nitta, T., 1987: Convective activities in the tropical western Pacific and their impact on the Northern Hemisphere summer circulation. J. Meteor. Soc. Japan, 65, 373-390.

Nordeng, T. E., 1994: Extended versions of the convective parameterization scheme at ECMWF and their impact on the mean and transient activity of the model in the tropics. ECMWF Research Department Tech. Memo. 206, 41 pp.

Pope, V. D., M. L. Gallani, P. R. Rowntree, and R. A. Stratton, 2000: The impact of new physical parameterizations in the Hadley Centre climate model: HadAM3. Climate Dyn., 16, 123-146.

Rayner, N. A., D. E. Parker, E. B. Horton, C. K. Folland, L. V. Alexander, D. P. Rowell, E. C. Kent, and A. Kaplan, 2003: Global analyses of sea surface temperature, sea ice, and night marine air temperature since the late nineteenth century. $J$. Geophys. Res., 108, 4407, doi:10.1029/2002JD002670.

Ricard, J. L., and J. F. Royer, 1993: A statistical cloud scheme for use in an AGCM. Ann. Geophys., 11, 1095-1115.

Rodwell, M. J., and B. J. Hoskins, 1996: Monsoons and the dynamics of deserts. Quart. J. Roy. Meteor. Soc., 122, 1385-1404.

—, and - 2001: Subtropical anticyclones and summer monsoons. J. Climate, 14, 3192-3211.

Roeckner, E., and Coauthors, 2003: The atmospheric general circulation model ECHAM5. Part I: Model description. Max Planck Institute for Meteorology Rep. 349, 140 pp. [Available online at http://www.mpimet.mpg.de/fileadmin/publikationen/ Reports/max_scirep_349.pdf.]

Seager, R., R. Murtugudde, N. Naik, A. Clement, N. Gordon, and J. Miller, 2003: Air-sea interaction and the seasonal cycle of the subtropical anticyclones. J. Climate, 16, 1948-1966.

Sui, C.-H., P.-H. Chung, and T. Li, 2007: Interannual and interdecadal variability of the summertime western North Pacific subtropical high. Geophys. Res. Lett., 34, L11701, doi:10.1029/ 2006 GL029204.

Sutton, R. T., and D. L. R. Hodson, 2007: Climate response to basin-scale warming and cooling of the North Atlantic Ocean. J. Climate, 20, 891-907.

Tao, S. Y., and S. Y. Xu, 1962: Circulation characteristics in association with persistent summer drought and flood in the Yangtze-Huaihe River reaches. Acta Meteor. Sin., 32, 1-18.

—, and L. X. Chen, 1987: A review of recent research on the East Asian summer monsoon in China. Monsoon Meteorology, Oxford Monogr. on Geology and Geophysics, Vol. 7, Oxford University Press, 60-92.

Tiedtke, M., 1989: A comprehensive mass flux scheme for cumulus parameterization in large-scale models. Mon. Wea. Rev., 117, 1779-1800. 
Ting, M., 1994: Maintenance of northern summer stationary waves in a GCM. J. Atmos. Sci., 51, 3268-3308.

Uppala, S. M., and Coauthors, 2005: The ERA-40 Re-Analysis. Quart. J. Roy. Meteor. Soc., 131, 2961-3012.

Wang, B., Q. Ding, X. Fu, I.-S. Kang, K. Jin, J. Shukla, and F. Doblas-Reyes, 2005: Fundamental challenge in simulation and prediction of summer monsoon rainfall. Geophys. Res. Lett., 32, L15711, doi:10.1029/2005GL022734.

Wang, H., 2001: The weakening of Asian monsoon circulation after the end of 1970's. Adv. Atmos. Sci., 18, 376-386.

Webster, P. J., A. M. Moore, J. P. Loschnigg, and R. R. Leben, 1999: Coupled ocean-atmosphere dynamics in the Indian Ocean during 1997-98. Nature, 401, 356-360.

Wu, B., and T. Zhou, 2008: Oceanic origin of the interannual and interdecadal variability of the summertime western Pacific subtropical high. Geophys. Res. Lett., 35, L13701, doi:10.1029/ 2008GL034584.

Wu, G., and Y. Liu, 2003: Summertime quadruplet heating pattern in the subtropics and the associated atmospheric circulation. Geophys. Res. Lett., 30, 1201, doi:10.1029/2002GL016209.

_, _ , and P. Liu, 1999: Spatially inhomogeneous diabatic heating and its impacts on the formation and variation of subtropical anticyclone, I. Scale analysis (in Chinese). Acta Meteor. Sin., 57, 257-263.

Wu, R., and B. P. Kirtman, 2005: Roles of Indian and Pacific Ocean air-sea coupling in tropical atmospheric variability. Climate Dyn., 25, 155-170.

Xin, X., R. Yu, T. Zhou, and B. Wang, 2006: Drought in late spring of South China in recent decades. J. Climate, 19, 3197-3206.

Yang, J., Q. Liu, S.-P. Xie, Z. Liu, and L. Wu, 2007: Impact of the Indian Ocean SST basin mode on the Asian summer monsoon. Geophys. Res. Lett., 34, L02708, doi:10.1029/2006GL028571.
Ye, D., and B. Zhu, 1958: Some Fundamental Problems of the General Circulation of the Atmosphere (in Chinese). Science Press, 159 pp.

Yu, R., and T. Zhou, 2007: Seasonality and three-dimensional structure of the interdecadal change in East Asian monsoon. J. Climate, 20, 5344-5355.

—, B. Wang, and T. Zhou, 2004: Tropospheric cooling and summer monsoon weakening trend over East Asia. Geophys. Res. Lett., 31, L22212, doi:10.1029/2004GL021270.

Zhang, G. J., and N. A. McFarlane, 1995: Sensitivity of climate simulations to the parameterization of cumulus convection in the Canadian Climate Centre general circulation model. Atmos.-Ocean, 33, 407-446.

Zhang, Q., Y. Qian, and X. Zhang, 2000: Interannual and interdecadal variations of the South Asia high (in Chinese). Chin. J. Atmos. Sci., 24, 67-78.

Zhou, T., and Z. Li, 2002: Simulation of the East Asian summer monsoon by using a variable resolution atmospheric GCM. Climate Dyn., 19, 167-180.

— , and R. Yu, 2005: Atmospheric water vapor transport associated with typical anomalous summer rainfall patterns in China. J. Geophys. Res., 110, D08104, doi:10.1029/2004JD005413.

,,$-- \mathrm{H}$. Li, and B. Wang, 2008: Ocean forcing to changes in global monsoon precipitation over the recent half-century. $J$. Climate, 21, 3833-3852.

- B. Wu, and B. Wang, 2009: How well do atmospheric general circulation models capture the leading modes of the interannual variability of Asian-Australian monsoon? J. Climate, 22, 1159-1173.

Zhu, Q., J. He, and P. Wang, 1986: A study of circulation differences between East-Asian and Indian summer monsoons with their interaction. Adv. Atmos. Sci., 3, 466-477. 